NBER WORKING PAPER SERIES

\title{
HAS MONETARY POLICY BECOME MORE EFFICIENT? A CROSS COUNTRY ANALYSIS
}

\author{
Stephen G. Cecchetti \\ Alfonso Flores-Lagunes \\ Stefan Krause \\ Working Paper 10973 \\ http://www.nber.org/papers/w10973 \\ NATIONAL BUREAU OF ECONOMIC RESEARCH \\ 1050 Massachusetts Avenue \\ Cambridge, MA 02138 \\ December 2004
}

We want to thank Michael Ehrmann and Frank Smets for their very useful suggestions, and the seminar participants at the University of Cambridge, London Business School, Nuffield College - Oxford, University of Arizona, European Central Bank, and the 2003 Econometric Society Winter Meetings for their comments. The views expressed herein are those of the author(s) and do not necessarily reflect the views of the National Bureau of Economic Research.

(C) 2004 by Stephen G. Cecchetti, Alfonso Flores-Lagunes, and Stefan Krause. All rights reserved. Short sections of text, not to exceed two paragraphs, may be quoted without explicit permission provided that full credit, including $\odot$ notice, is given to the source. 
Has Monetary Policy Become More Efficient? A Cross Country Analysis

Stephen G. Cecchetti, Alfonso Flores-Lagunes, and Stefan Krause

NBER Working Paper No. 10973

December 2004

JEL No. E52, E58

\begin{abstract}
$\underline{\text { ABSTRACT }}$
Over the past twenty years, macroeconomic performance has improved in industrialized and developing countries alike. In a broad cross-section of countries inflation volatility has fallen markedly while output variability has either fallen or risen only slightly. This increased stability can be attributed to either: 1) more efficient policy-making by the monetary authority, 2) a reduction in the variability of the aggregate supply shocks, or 3) changes in the structure of the economy. In this paper we develop a method for measuring changes in performance, and allocate the source of performance changes to these two factors. Our technique involves estimating movements toward an inflation and output variability efficiency frontier, and shifts in the frontier itself. We study the change from the 1980s to the 1990s in the macroeconomic performance of 24 countries and find that, for most of the analyzed countries, more efficient policy has been the driving force behind improved macroeconomic performance.
\end{abstract}

\author{
Stephen G. Cecchetti \\ International Business School \\ Mail Stop 021 \\ Brandeis University \\ P.O. Box 9110 \\ Waltham, MA 02454 \\ and NBER \\ cecchetti@brandeis.edu
}

\author{
Alfonso Flores-Lagunes Stefan Krause \\ Department of Economics \\ Department of Economics \\ The University of Arizona \\ McClelland Hll 401 \\ Emory University \\ Atlanta, GA 30322 \\ Tucson, AZ 85721 \\ skrause@emory.edu \\ alfonso@eller.arizona.edu
}




\section{Introduction}

Over the past twenty years, macroeconomic performance has improved markedly in industrialized and developing countries alike. Both inflation and real growth are more stable now than they were a decade ago. Looking at a sample of 24 countries comparing the 1980s and the 1990s, we see that 20 experienced lower inflation variability, while output volatility was lower in 15 .

There are a number of candidate explanations for this widespread improvement in macroeconomic outcomes. One possibility is that the world has become a more stable place. If there are no shocks hitting an economy, it will surely be more stable. Alternatively, monetary policymakers may have become more skillful at implementing policies to meet their stabilization objectives. That is, the monetary policies of the 1990s may have been more efficient than those of the 1980s.

The purpose of this paper is to develop a method for measuring the contribution of improved monetary policy to observed changes in macroeconomic performance and then use it to explain the observed increase in macroeconomic stability in a cross-section of countries. Our technique involves examining changes in the variability of inflation and output over time. We estimate a simple macroeconomic model of inflation and output for each country and use it to construct an output-inflation variability efficiency frontier. Specifically, for each country we specify the dynamics of inflation and output as a function of the interest rate - our measure of the central bank policy instrument - and some additional exogenous variables. Using the estimated model, we are able to compute the output-inflation efficiency frontier as the solution to a simple optimization problem in which policymakers are assumed to minimize a loss function that is a weighted average of the squared deviations of inflation and output from their target levels.

We estimate this frontier for two sample periods, the 1980s and the 1990s. Next, we compute the change in macroeconomic performance for each country using a weighted sum 
of inflation and output volatility, and examine how much of that change can be accounted for by a movement in the variability frontier, and how much is a movement toward the frontier itself. Shifts in the variability frontier are attributed to changes in the volatility of supply shocks and the structure of the economy, while movements toward the frontier measure improvements in policy efficiency. Thus, our calculations allow us to parse improvements in macroeconomic performance into the portion that can be accounted for by more efficient policy and the part that can be attributed to lower supply shock variability and changes in the structure of the economy.

Throughout the paper, we assume that improved macroeconomic policy is better monetary policy, and that the major tool for stabilization policy is the central bank's adjustment of the interest rate. In this view, improved efficiency reflects more skillful central bankers. Clearly, there are factors beyond the proficiency of monetary policymakers per se that will lead to improved overall economic outcomes. Specifically, the environment has to be one in which the policymakers can actually do their jobs. If, as is sometimes the case, central bankers have little control over financial affairs, then the level of their expertise is irrelevant. As Cecchetti and Krause (2001) discuss, whether or not a central banker can actually stabilize the economy will depend on the financial structure in that country. Furthermore, changes in independence, credibility and transparency of policy can affect the ability of policymakers to perform effectively.

Finally, there are a myriad of fiscal, trade and labor market policies that affect macroeconomic structure and so will have an impact both on the location of the efficiency frontier and on monetary policy effectiveness. For instance, changes in the degree of nominal rigidity or inflation expectations may affect the shape and location of the efficiency frontier via changes in the structure of the economy. Also, improvements in the management of final goods inventories may reduce the effects of supply disturbances to the economy (Kahn, McConnell and Pérez-Quirós, 2002), thus affecting the frontier. Therefore all these factors would show 
up as changes in the variability of aggregate supply shocks in our method, and thus our definition of variability of supply shocks necessarily includes some changes in the structure of the economy not captured by the slope of the efficiency frontier. While our technique is too coarse to distinguish among all of these possible causes of the changes that we document, we consider it a necessary first step.

The remainder of the paper is divided into six sections. In Section 2, we take a preliminary look at the data on macroeconomic outcomes for the 24 countries in our sample. Section 3 introduces the proposed method to analyze the changes in macroeconomic performance. Section 4 describes the procedure to obtain the efficiency frontier for monetary policy using a linear structural model that captures the dynamics of each of the economies in question. Section 5 presents and discusses the main results. Our results suggest that improved monetary policy has played a stabilizing role in 21 of the 24 countries. Seventeen countries experienced reduced supply shock variability, but overall this had a modest impact on performance. Importantly, we find that our results are robust to alternative assumptions regarding the preferences and targets of the monetary authority. Section 6 discusses some explanations for the cross-country differences in the changes in macroeconomic performance and policy efficiency, while Section 7 concludes the paper.

\section{Empirical Facts}

We study a sample of 24 countries, ranging from large industrial countries to small developing ones. ${ }^{1}$ Selection into our sample resulted primarily from data availability, with the absence of reliable data on short-term interest rates serving as the main restriction. Our first step is to take a simple look at the data on macroeconomic performance over the past 20 years. With this in mind, we analyze the behavior of inflation and output for two periods, 1983

\footnotetext{
${ }^{1}$ The list includes Australia, Austria, Belgium, Canada, Chile, Denmark, Finland, France, Germany, Greece, Ireland, Israel, Italy, Japan, Korea, Mexico, Netherlands, New Zealand, Portugal, Spain, Switzerland, Sweden, the United Kingdom, and the United States.
} 
to 1990 and 1991 to 1998, using quarterly data. We choose 1983 as the starting year as a result of data availability for the interest rate, while the choice of 1998 as the final year of the sample is due to the fact that this is the last year before the European Monetary Union comes into effect, discontinuing independent interest rate policy in 11 of the countries.

To measure inflation and output volatility, our baseline assumption is that policymakers are interested in achieving an inflation target of $2 \%$ and in minimizing the variability of output around its potential level. ${ }^{2}$ We discuss these assumptions at length in Section 5, where we consider alternative targets in our empirical analysis.

Figure 1 presents the change in the variability of inflation and output for the 24 countries of interest. We can draw several conclusions from these data. First, in 11 countries, both output and inflation variability fell, implying an unambiguous improvement in performance. In an additional 9 countries, inflation variability fell, while output variability rose. In fact, for all members of the European Union, except Germany, inflation variability fell between the 1980s and the 1990s. This surely reflects the increasing importance placed by central banks on explicit or implicit inflation targeting in the 1990s. ${ }^{3}$ Finally, we note that seven out of the nine countries in which output variability rose were in the EU. This is consistent with the conclusions in Cecchetti and Ehrmann (2001) that the shift to inflation targeting can move countries along an output-inflation variability frontier, lowering the latter at the expense of the former. Importantly, though, none of the countries in our sample experienced an increase in both inflation and output variability.

\footnotetext{
${ }^{2}$ For each country, we measure potential output as Hodrick-Prescott filtered industrial production.

${ }^{3}$ See Fry, Julius, Mahadeva, Roger and Sterne (2000) for a discussion of the changes in central bank targeting procedures.
} 
Figure 1: Change in inflation and output variability

(83-90 vs. 91-98)

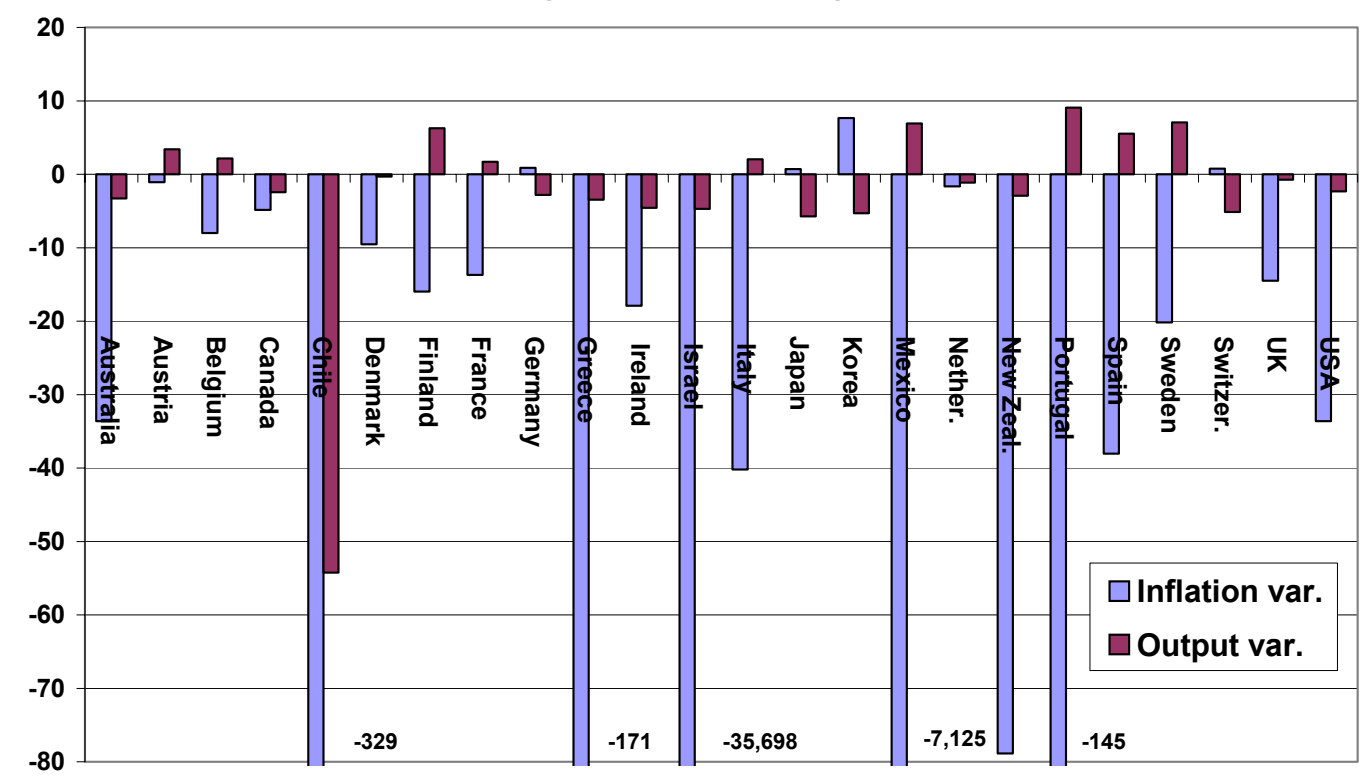

Inflation variability is measured as the squared deviation from a $2 \%$ target level $(x 10,000)$

Output variability is measured as the squared deviation from an H-P trend $(x 10,000)$

We use the information in Figure 1 to construct measures of macroeconomic performance

changes. In the next section, we describe how to obtain these measures and, furthermore, how to identify the sources of the performance changes.

\section{Measuring the Sources of Macroeconomic Perfor- mance Changes}

Our goal is to divide changes in macroeconomic performance into the portion that is due to changes in the variability of shocks and the part that can be ascribed to changes in policy efficiency. To do this, we rely on the use of the inflation-output variability tradeoff, or efficiency frontier. As we explain, increases or decreases in the variability of supply shocks shift this frontier, while movements toward or away from the trade-off arise from improvements or declines in policy efficiency. Since our measures can be derived using a 
simple two-dimensional graph, we begin with an intuitive explanation. Section 4 contains analytical derivations that are based on a specific, and empirically tractable, macroeconomic model.

The concept of an inflation-output variability frontier is most easily understood by considering a simple economy that is affected by two general types of disturbances, both of which may require policy responses. These are aggregate demand shocks - which move output and inflation in the same direction - and aggregate supply shocks - which move output and inflation in opposite directions. Since monetary policy can move output and inflation in the same direction, it can completely offset aggregate demand shocks. By contrast, aggregate supply shocks will force the monetary authority to face a trade-off between the variability of output and that of inflation. ${ }^{4}$

Figure 2: Efficiency frontier and performance point

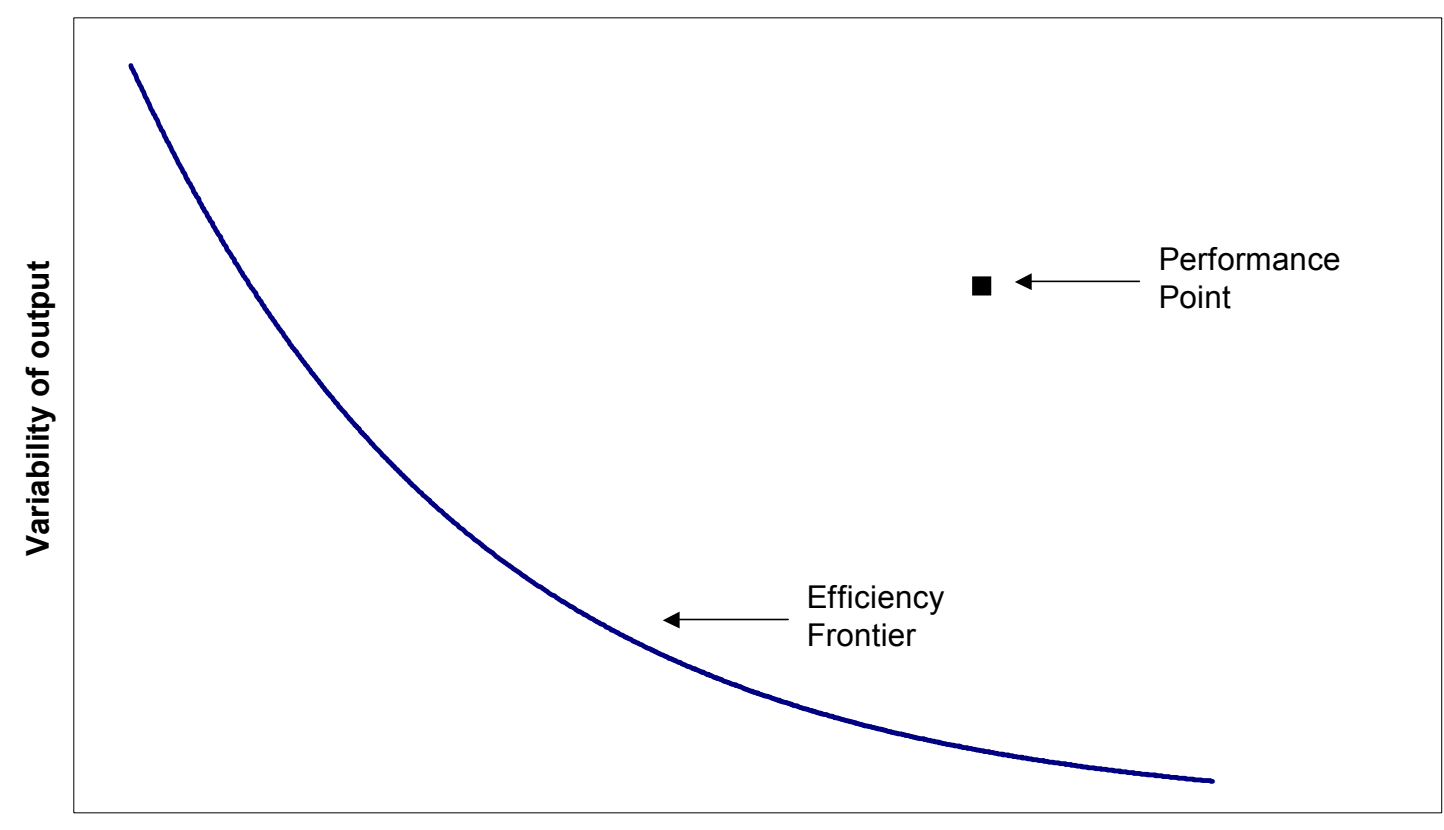

Variability of inflation

\footnotetext{
${ }^{4}$ For a simple algebraic model and a discussion of the derivation of the output-inflation variability frontier see Cecchetti and Ehrmann (2001).
} 
This trade-off allows us to construct an efficiency frontier for monetary policy that traces the points of minimum inflation and output variability. This is the curved line in Figure 2, known in the literature as the Taylor Curve (Taylor, 1979). The location of the efficiency frontier depends on the variability of aggregate supply shocks - the smaller such variability, the closer the frontier will be to the origin; while the slope of the frontier is determined by the structure of the economy. If monetary policy is optimal, the economy will be on this curve. The exact point depends on the policymaker's preferences for inflation and output stability. When policy is sub-optimal, the economy will not be on this frontier. Instead, the performance point will be up and to the right, with inflation and output variability both in excess of other feasible points. Movements of the performance point toward the frontier are an indication of improved policymaking.

Our goal is to measure both movements in the performance point and shifts in the policy efficiency frontier. In order to obtain a summary measure of performance, we assume that the objective of policymakers is to minimize a weighted sum of inflation and output variability. This is the standard quadratic loss function used in most contemporary analyses of central bank policy. We can summarize this loss as: ${ }^{5}$

$$
\operatorname{Loss}=\lambda \operatorname{Var}(\pi)+(1-\lambda) \operatorname{Var}(y), 0 \leq \lambda \leq 1
$$

where $\pi$ is inflation, $y$ is output, and $\lambda$ is the policymaker's preference parameter - Cecchetti and Ehrmann (2001) call this the policymaker's inflation variability aversion. We will assess an economy's performance, and changes in macroeconomic outcomes, using measures based on this loss. We note that we have not included a discount factor in the loss function, since our measures of performance and policy efficiency described below only consider comparing two periods of interest.

Obviously, computation of the loss requires a value of the preference parameter $\lambda$, which

\footnotetext{
${ }^{5}$ We note that, in what follows, $\operatorname{Var}(\cdot)$ stands for variability with respect to a target of the variable in question, and it is not necessarily equal to variance around the mean.
} 
can be either estimated within our method or can be chosen based on plausible values obtained elsewhere. ${ }^{6}$ Importantly, our results are robust to both approaches and also to a plausible range of values for $\lambda$. We defer discussion of how $\lambda$ is chosen until Section 5.1. For the time-being, we will assume that $\lambda$ is known.

Given the policymaker's preferences, we can define the scalar measures of changes in performance, changes in policy efficiency and changes in the variability of supply shocks that we will use in our empirical analysis. First, macroeconomic performance is simply a weighted average of the observed variability of output and inflation. We call this $P_{i}(i=1,2$; periods), and define it as follows:

$$
P_{i}=\lambda \operatorname{Var}\left(\pi_{i}\right)+(1-\lambda) \operatorname{Var}\left(y_{i}\right)
$$

The change in macroeconomic performance is just the change in $P$ from one period to the next, $\Delta P=P_{1}-P_{2}$. If $\Delta P$ is positive we interpret this as a performance gain. To allow for a proper comparison across periods, when computing $\Delta P$ we assume $\lambda$ to be constant. ${ }^{7}$ The alternative of allowing $\lambda$ to vary across periods renders $P_{1}$ and $P_{2}$ incomparable, for example, $\Delta P$ can indicate a decrease in macroeconomic performance even though both the variability of output and inflation fall.

This change in performance reflects both shifts in the variability frontier and toward or away from the frontier. We identify shifts in the efficiency frontier by measuring changes in the weighted sum of the optimal variabilities of output and inflation. Since the efficiency frontier shifts if the variability of supply shocks changes, we refer to this as our measure of the variability of supply shocks, and it is given by:

$$
S_{i}=\lambda \operatorname{Var}\left(\pi_{i}\right)^{*}+(1-\lambda) \operatorname{Var}\left(y_{i}\right)^{*}
$$

where $\operatorname{Var}\left(\pi_{i}\right)^{*}$ and $\operatorname{Var}\left(y_{i}\right)^{*}$ are the variabilities of inflation and output under optimal

\footnotetext{
${ }^{6}$ There is a growing literature trying to estimate the preferences of policymakers. See for instance Cecchetti and Ehrman (2001), Dennis (2001) and Favero and Rovelli (2003).

${ }^{7}$ We note, however, that our findings are robust to computing the measures using estimated preferences from the first or second period. These results are available upon request.
} 
policy for period $i$, respectively. $\Delta S=S_{2}-S_{1}$ is the measure we use to quantify the change in the variability of supply shocks. We define $\Delta S$ in this fashion, instead of the one we employ to define $\Delta P$, so that we can interpret negative values of $\Delta S$ as an indicator that the shocks hitting the economy have been smaller in absolute value, and conversely.

\section{Figure 3: Derivation of the Optimal Variabilities}

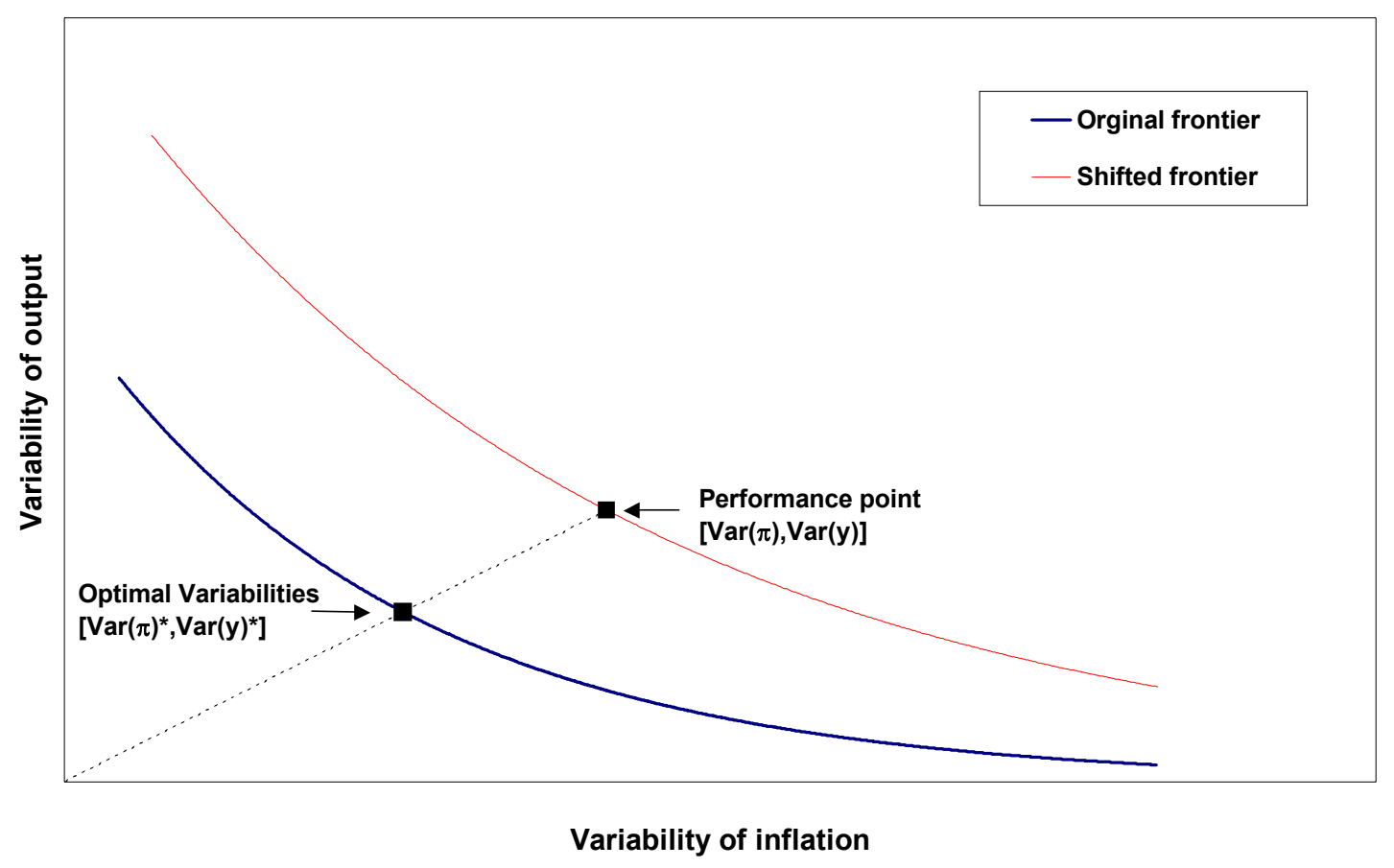

To determine $\operatorname{Var}\left(\pi_{i}\right)^{*}$ and $\operatorname{Var}\left(y_{i}\right)^{*}$ we use the following procedure. Beginning with Figure 2, we shift the efficiency trade-off homothetically outward until it passes through the performance point representing the observed variabilities of inflation and output. Figure 3 shows the original and shifted frontiers. We determine the optimal variabilities as the point on the original frontier associated with this same performance point. In Section 4 we describe the derivation of the optimal variability point analytically. A geometrical interpretation of the optimal variability point is the intersection point of the original frontier with a line from the origin to the performance point. 
We gauge monetary policy efficiency by looking at the distance between actual performance and performance under optimal policy. Policy inefficiency for each period is given by:

$$
E_{i}=\lambda\left[\operatorname{Var}\left(\pi_{i}\right)-\operatorname{Var}\left(\pi_{i}\right)^{*}\right]+(1-\lambda)\left[\operatorname{Var}\left(y_{i}\right)-\operatorname{Var}\left(y_{i}\right)^{*}\right]
$$

The definitions of $P_{i}$ and $S_{i}$ imply that $E_{i}$ can be also obtained as the difference $P_{i}-S_{i}$. Since $E_{i}$ will be smaller the closer actual outcomes are to the optimal, our measure of the change in policy efficiency follows immediately as the difference $\Delta E=E_{1}-E_{2}$. We interpret positive values of $\Delta E$ as increases in the efficiency of monetary policy. When $\Delta E$ is negative, it suggests that policymaking has deteriorated as the economy has moved further away from the frontier.

Finally, we use the division of the change in performance into its two components to calculate the proportion that can be accounted for by improved policy. The measure we use is given by the following ratio:

$$
Q=\frac{\Delta E}{|\Delta P|}
$$

Given that the absolute value of the performance gain is in the denominator, a positive value of $Q$ implies improved policy efficiency, whereas a negative $Q$ implies that policy has become less efficient. If we observe a macro performance gain at the same time as policy has become more efficient and the variability of supply shocks has become smaller, $Q$ will be between 0 and 1 and can be interpreted as the relative contribution of a more efficient policy towards the achievement of a macro performance gain.

Implementing the procedure we have just described requires us to follow several steps. First we must construct and estimate a dynamic model of inflation and output for each of countries for the periods we are interested in. Then, using these estimates and an unrestricted policy rule represented by the interest rate (the policymakers instrument), we can construct each period's efficiency frontier and performance point. With these in hand and estimating or choosing plausible values of the preference parameter $\lambda$, we are then able to compute $\Delta P$, 
$\Delta E$, and $Q$. This is the task of the remainder of the paper.

\section{Estimating the Efficiency Frontier}

The efficiency frontier is constructed as follows. Beginning with the quadratic loss function representing trade-offs among combinations of inflation and output variability, we treat policy as a solution to an optimal control problem in which the interest rate path is chosen to place the economy at the point on the variability frontier that minimizes the loss. Formally, we compute the policy reaction function that minimizes the loss, subject to the constraint that is imposed by the structure of the economy. For a given loss function, with a particular weighting of inflation and output variability $(\lambda)$, we are able to plot a single point on the efficiency frontier. As we change the relative weight assigned to the variability of inflation and output in the loss function, we are able to trace out the entire efficiency frontier.

Our econometric procedure has four steps. First, in Section 4.1, we estimate simple structural models of inflation and output for each of the 24 countries in our sample. Next, in Section 4.2, we undertake a number of diagnostic and specification checks to establish the adequacy of our empirical models. In Section 4.3, we describe the construction of the efficiency frontier from the model estimates. Finally, in Section 4.4, we describe a simulationbased approach to assess the reliability of the estimated measures.

\subsection{Structural Model}

Parsimony is an important consideration in choosing a specification to approximate the dynamics of the economies under consideration. As a result, we build models that satisfy a minimal set of key conditions. First, the model should be general enough so that it can be estimated, with only minor changes, for all of the 24 countries in the sample. Second, the model should fit the data reasonably well and yield theoretically plausible estimates to be used in the construction of the efficiency frontier. Finally, the model must be simple enough 
so that we can apply simulation techniques to evaluate the reliability of the quantities of interest.

With these requirements in mind, we consider linear two-equation systems for each country based on a dynamic aggregate demand - aggregate supply model. The basic model consists of the following two equations:

$$
\begin{aligned}
y_{t} & =\sum_{l=1}^{2} \alpha_{1 l} i_{t-l}+\sum_{l=1}^{2} \alpha_{1(l+2)} y_{t-l}+\sum_{l=1}^{2} \alpha_{1(l+4)} \pi_{t-l}+\alpha_{17} x_{t-1}+\varepsilon_{1 t} \\
\pi_{t} & =\sum_{l=1}^{2} \alpha_{2 l} y_{t-l}+\sum_{l=1}^{2} \alpha_{2(l+2)} \pi_{t-l}+\alpha_{25} x_{t-1}+\varepsilon_{2 t}
\end{aligned}
$$

The first equation represents an aggregate demand curve. It relates detrended log industrial production, $y$, to two of its own lags, two lags of the nominal interest rate, $i$, two lags of demeaned inflation, $\pi$, and one lag of demeaned external price inflation, $x$, to account for the inter-relation between the economy of interest and its main trading partner. ${ }^{8}$ The second equation is an aggregate supply curve. Here, inflation is assumed to be a function of two of its own lags, representing inflation expectations, two lags of detrended log industrial production and one lag of demeaned external price inflation. The error terms $\varepsilon_{1}$ and $\varepsilon_{2}$ are assumed to be mean zero and constant variance.

This model is a two-lagged vector autoregressive (VAR) model with three endogenous variables (inflation, industrial production and interest rates) and the restriction that interest rates do not enter into the inflation equation. ${ }^{9}$ This formulation is based on the empirical observation that monetary policy actions affect industrial production before inflation (see, for instance, the empirical model in Rudebusch and Svensson (1999) and the theoretical model of Svensson (1997), among others). We formally test this restriction in the next section and find statistical evidence supporting it.

\footnotetext{
${ }^{8}$ External price inflation is measured as the sum of the annualized devaluation rate and the inflation of the main trading partner. See Appendix I.

${ }^{9}$ We estimate below an additional equation for the interest rate that contains lags of all endogenous variables in order to obtain impulse response functions (IRFs). However, we only need the estimates of the two-equation model in (6) and (7) to obtain the efficiency frontier.
} 
We estimate equations (6) and (7) for each country separately in each subperiod with quarterly data, using ordinary least squares (OLS). In some cases we also included dummy variables to account for currency crises, sharp recessions, or structural changes. A description of the variables used for each country is included in Appendix I. Appendix II lists all of the data sources.

\subsection{Diagnostic and Specification Analysis}

In this section we undertake a series of diagnostic and specification tests of our two-equation structural model. We begin by discussing the time-series properties of our data, and then move on to a comparison of the restricted model to a more general one that encompasses it.

Our first test of model adequacy is to establish that the estimated residuals are independent. Autocorrelation would be evidence of misspecification. Using a Durbin-h test applied to the residuals of the two-equation model (estimated for both periods and all countries using OLS) we are unable to reject the null hypothesis of no autocorrelation at a $10 \%$ level or higher for all of the countries in our sample. ${ }^{10}$

For the derivation of the efficiency frontier and the application of the simulation method proposed below to asses the reliability of the estimated measures, it is necessary that the residuals be stationary. This requires either that the demeaned and detrended endogenous variables be stationary themselves, or that there exists some cointegrating relationship among them. Since the distinction between these two is immaterial to us, we simply test for the non-stationarity of the estimated residuals. Using the Phillips-Perron (1988) test we are able to reject the null hypothesis of non-stationarity at the $1 \%$ significance level in all countries for both periods. This is strong support for the compatibility of our model specification with the integration properties of the data.

Since we are estimating a system of two equations separately, there might exist some

\footnotetext{
${ }^{10}$ The only exceptions are the output equation for the first period in the case Belgium, for which the p-value of the Durbin-h test is 0.081 , and the inflation equation for the first period in the case of Mexico, for which the p-value of the Durbin-h test is 0.096 .
} 
cross correlation between the error terms of the equations that can be exploited to obtain more efficient estimators with a system estimator such as seemingly unrelated regressions (SUR). To check whether the separate estimation of each equation is efficient relative to system estimation, we tested the contemporaneous correlation of the error terms of the twoequation model for each period in each of the countries in our sample. We were not able to reject the null hypothesis of zero contemporaneous correlation at a $10 \%$ level or higher in both periods for all countries with the exception of two. In these cases, we are not able to reject the null hypothesis at the $5 \%$ and $1 \%$ levels. ${ }^{11}$ This provides justification for the single-equation estimation of the model.

Another interesting exercise is to compare the estimated coefficients across subperiods using structural stability (Chow) tests. If evidence is found that the estimated coefficients differ across subperiods for a country, it is an indication that the structure of the economy has somehow changed and that the efficiency frontier that policymakers face is different. Our measures are designed to take this into account when evaluating monetary policy. Nevertheless, even if no structural change in the coefficients is found, our measures are still meaningful since in this case the frontier has changed little and thus policy will be credited for the change in macro performance. With this in mind, we find evidence (at the $10 \%$ level) of structural change across periods in either equations (6) or (7) for 16 countries, and among the remaining 8 countries, 3 of them show evidence of structural change at a $14 \%$ level. There is, therefore, evidence that for most of the countries the frontiers have changed substantially from the 1980 s to the 1990 s.

We next test the specification of our structural model by testing the restrictions that it imposes on an unrestricted vector autoregressive (VAR) model. In an unrestricted VAR, the right-hand-side variables in both regressions would be identical, with the number of

\footnotetext{
${ }^{11}$ Chile in the first subperiod has a p-value of 0.016; while Denmark in the second subperiod has a p-value of 0.044; however, in neither of these cases are the SUR coefficients and standard errors significantly different from the ones obtained through the OLS estimation.
} 
lags on each regressor, and the regressors themselves, being the same. Relative to a general unrestricted setup, our model omits the interest rate from the right-hand-side of the supply equation (7).

We compare our models with the corresponding unrestricted VAR models based on three different criteria. First, we test the restriction using standard (exact) F and (asymptotic) Lagrange Multiplier (LM) statistics. Next, we provide two more comparisons, one based on the theoretical plausibility of the Impulse Response Functions (IRFs) yielded by each model, and the other based on model selection criteria such as the Akaike and Bayesian information criteria (AIC and BIC, respectively). The IRFs show the response function of inflation to a change of 100 basis points in the interest rate. To be able to compare the IRFs yielded by the two models, we add an identical interest rate equation to each of them, which results in IRFs that will only differ due to the restrictions imposed in the equation for inflation in the structural model. ${ }^{12}$

Beginning with the VAR comparison, we find that, with the exception of Australia and Switzerland, the restrictions implied in equation (7) of the structural model are not rejected by either the $\mathrm{F}$ or the LM tests for the first period at a significance level of $5 \%$ or higher. ${ }^{13}$ Nevertheless, restricting the coefficients on the lagged interest rate to zero for these two countries actually yields more sensible IRFs of inflation. For the second period, 14 countries fail to reject the restrictions at a $5 \%$ level or more, while for the rest the restrictions are rejected by at least one of the tests. ${ }^{14}$ With the exception of two countries (Switzerland and the US), restricting the coefficients on the lagged interest rate to zero in the inflation equation eliminates the so-called price-puzzle (Sims, 1992) in the IRFs, whereas for Switzerland and the US. the price-puzzle is less pronounced under the structural model. ${ }^{15}$ We regard this as

\footnotetext{
${ }^{12}$ The impulse response functions and the value of the statistics of all diagnostic tests are not presented here to save space, but they are available upon request from the authors.

${ }^{13}$ In fact, for 19 countries the p-value of both tests is above 0.10 .

${ }^{14}$ These countries are Australia, Canada, Denmark, Germany, Korea, Netherlands, New Zealand, Spain, Switzerland and the U.S.

${ }^{15} \mathrm{~A}$ rise in inflation following an increase in the nominal interest rate is commonly referred to as the price
} 
evidence that our structural model is correctly specified relative to a VAR. However, since some countries still present prize-puzzles under our preferred specification, we also provide below results for a restricted sample that ignores these countries.

Finally, we also evaluate the goodness of fit of our proposed model by using the Akaike and Bayesian information criteria (AIC and BIC). These two model selection criteria are functions of the residual sum of squares of the models and differ in the degree to which they penalize the estimation of extra parameters, with the BIC penalty being higher. Given the relatively small number of degrees of freedom resulting from the estimation in each period, we consider the $\mathrm{BIC}$ is a better criterion for comparing the two models. When looking at each country in each of the two periods, the BIC criteria tends to favor our structural specification over an unrestricted VAR. Considering both information criteria together, for 13 countries the structural model is supported over the VAR specification. ${ }^{16}$ Apart for only 4 countries where the VAR is favored, in the remaining 7 the evidence is mixed. In sum, according to the information criteria the restrictions implied by the structural model do not seem inadequate.

Overall, we interpret the evidence as supporting the restrictions imposed by the structural model vis-a-vis the overparametrized VAR model, and therefore supporting the specification of the structural model. In the following section, we use the model in (6) and (7) to construct the efficiency frontier, which will be then used to compute the measures of interest.

We finish this section by pointing out that when interest lies on a single country, a more detailed econometric model can be used to estimate the structure of the economy needed to apply our method. For instance, Cecchetti, Flores-Lagunes and Krause (2001) perform a more detailed analysis for Mexico, in which additional variables that help improve the structural model are considered and structural change tests for unknown break point are puzzle.

${ }^{16}$ Among the 13 countries are Korea and Netherlands, for which the restrictions where rejected for the second period. 
employed to divide the sample, among other things. In this particular case of Mexico, it turns out that the results in the detailed analysis are very similar to the ones obtained below. ${ }^{17}$

\subsection{Constructing the Efficiency Frontier}

With estimates of the structural model in hand, we turn to the construction of the efficiency frontier. As described above, we derive the frontier by minimizing an objective function subject to the constraints imposed by the dynamic structure of the economy.

To begin, we assume that the central bank chooses an interest rate path to minimize a weighted average of the squared deviations of inflation and output from some target values. Consistent with the definition of the loss function in (1), we write this as:

$$
E[L]=E\left[\lambda\left(\pi_{t}-\pi^{*}\right)^{2}+(1-\lambda)\left(y_{t}-y^{*}\right)^{2}\right]
$$

where $\pi^{*}$ and $y^{*}$ are the policymaker's targets for inflation and output, respectively. This loss function does not include the interest rate or the exchange rate, since we assume that the fundamental concern of a central bank is domestic macroeconomic performance as measured by output and price stability. We note that even though reducing the volatility in the interest rate is not considered explicitly as an argument in the loss function, the dynamic structure of the economy may imply that the feedback rule presents interest rate persistence.

Our baseline assumption is that the inflation target for all countries is $2 \%$, and that monetary authorities want to keep industrial production as close as possible to its potential level, computed by applying the H-P filter. We explore the robustness of our results to different targets of both inflation (using average inflation for each period and H-P filtered inflation) and output (using a log-linear trend).

\footnotetext{
${ }^{17}$ Cecchetti, Flores-Lagunes and Krause (2001) consider the subperiods 1982:I-1988:IV and 1991:I-1997:IV, average output growth as output target, and targets for inflation of $3.58 \%$ and $2.70 \%$, which correspond to the average inflation rate of the US for each period. Using a slightly different measure for the contribution of policy, we estimate it at $93 \%$ of the macro performance gain. As we report in section 5.2, our estimate of this contribution is $94.2 \%$
} 
For the purposes of exposition, it is useful to rewrite the basic structural model in (6)-(7) using its state-space representation,

$$
\begin{gathered}
Y_{t}=B Y_{t-1}+c i_{t-1}+D X_{t-1}+v_{t} \\
\text { where: } Y_{t}=\left[\begin{array}{c}
i_{t-1} \\
y_{t} \\
y_{t-1} \\
\pi_{t} \\
\pi_{t-1}
\end{array}\right] ; B=\left[\begin{array}{ccccc}
0 & 0 & 0 & 0 & 0 \\
\alpha_{12} & \alpha_{13} & \alpha_{14} & \alpha_{15} & \alpha_{16} \\
0 & 1 & 0 & 0 & 0 \\
0 & \alpha_{21} & \alpha_{22} & \alpha_{23} & \alpha_{24} \\
0 & 0 & 0 & 1 & 0
\end{array}\right] ; \\
c=\left[\begin{array}{c}
1 \\
\alpha_{11} \\
0 \\
0 \\
0
\end{array}\right] ; D=\left[\begin{array}{c}
0 \\
\alpha_{17} \\
0 \\
\alpha_{25} \\
0
\end{array}\right] ; X_{t}=\left[p x_{t}\right] ; v_{t}=\left[\begin{array}{c}
0 \\
\varepsilon_{1 t} \\
0 \\
\varepsilon_{2 t} \\
0
\end{array}\right]
\end{gathered}
$$

The policymaker's problem is to choose a path for the interest rate, $i_{t}$, in order to minimize (8), subject to the constraints imposed by (9). The linear-quadratic nature of the problem ensures that the solution for the control variable, the interest rate, will be linear. We write this as:

$$
i_{t}=\Gamma Y_{t}+\Psi
$$

where $\Gamma$ is the vector of reaction coefficients of the monetary authority to inflation and output changes and $\Psi$ is a constant term which depends on $B, c, D$ and the target values for inflation and output. ${ }^{18}$ Equation (10) represents an unrestricted monetary policy rule (See Rudebusch and Svensson, 1999), in which the degree of interest rate persistence can be observed since $i_{t-1}$ is a component of $Y_{t} \cdot{ }^{19,20}$

The control problem is solved by finding $\Gamma$ such that: ${ }^{21}$

$$
\Gamma=-\left(c^{\prime} H c\right)^{-1} c^{\prime} H B
$$

\footnotetext{
${ }^{18}$ See Chow (1975), pp. 158-159.

${ }^{19}$ As an example of how interest rate persistence arises, consider the case of the US. In the first (second) period, the coefficient on the lagged interest rate in the estimated interest rate equation is $0.74(0.80)$, which arises from an estimated value of 0.85 (0.89) on the lagged coefficient on output in equation (6), and an estimated value of 1.16 (1.23) on the lagged coefficient on inflation in equation (7).

${ }^{20}$ The estimated interest rate equations for the 24 countries are available upon request from the authors.

${ }^{21}$ For a technical exposition of this procedure see Chow (1975), pp. 156-160.
} 
and

$$
H=\Lambda+(B+c \Gamma)^{\prime} H(B+c \Gamma)
$$

where $\Lambda$ is an $5 \times 5$ matrix containing the relative weights given to output and inflation variability on the second and fourth diagonal elements, respectively, and zeros elsewhere.

Following this procedure once for a given value of $\lambda$ provides us with a single point on the efficient frontier. By varying $\lambda$ we are able to trace out an entire curve similar to the one in Figure 2.

Given this estimate of the efficiency frontier, as we explained in Section 3, we perform a homothetic shift of the frontier so that it passes through the data point given by the observed variabilities of inflation and output. This point will imply a certain ratio of the variabilities of inflation and output. We determine the optimal variabilities of inflation and output by the point on the original frontier associated with that same ratio.

We use the estimated efficiency frontier to obtain the measures of interest presented in Section $3 .^{22}$ These measures (to be reported in Section 5) are simply estimates and not the true values of the quantities of interest. For this reason, in the next section, we describe the method we use to evaluate their reliability as estimates of the true measures.

\subsection{Assessing the Reliability of the Measures}

The main hurdle we face in evaluating the reliability of our measures is that the typical statistical tools (such as the Delta method) are difficult to apply, given that our estimates result from a nonlinear dynamic optimization procedure. To overcome this problem we use simulation methods to construct an empirical distribution for the estimated measures. Specifically, we employ the parametric recursive bootstrap (Freedman and Peters, 1984) to obtain a number of "pseudo" samples for each country. These samples are used to compute replications of the measures and thus construct their empirical distributions.

\footnotetext{
${ }^{22}$ The estimated frontiers for the 24 countries in each subperiod are available from the authors upon request.
} 
The recursive bootstrap used here assumes that the estimated model for each country in equations (6) and (7) is correctly specified, and that the corresponding error terms are independent but not identically distributed (inid). These two assumptions are sufficient conditions to apply the parametric recursive bootstrap. In Section 4.2, we provided some evidence about the validity of our specification by comparing it to a more general model (the unrestricted VAR). In addition, the inid assumption is satisfied by the stationarity and lack of serial correlation in the estimated residuals (see Section 4.1).

We resample with replacement from the matrix consisting of both estimated residuals from both equations of the structural model. The bootstrap sample of industrial production and inflation is obtained in a recursive fashion assuming the other variables in the model and the initial values of both industrial production and inflation are given (i.e. we use their original values). Finally, we iterate this process a number of times to obtain replications for the measures. ${ }^{23}$

We obtain 1,000 bootstrap samples and estimate the structural model, the efficiency frontier, and the measures of interest. The replications of the measures are used to mediancorrect the estimated measures. The median correction is performed to obtain more robust estimates of the central tendency parameter of the corresponding distributions; ${ }^{24}$ we note, however, that the median corrections are small and in no case do they change the sign of the estimates, which provides additional support for our specification. ${ }^{25}$ The replications are also used to compute the probability that the estimated measure is of the opposite sign. This probability represents how likely is that the measure is not estimated in the right direction.

\footnotetext{
${ }^{23}$ For a detailed discussion of the procedure see Li and Maddala (1996).

${ }^{24}$ In general, a median corrected estimator is obtained with the following formula:

$$
\hat{\beta}_{M C}=2 \hat{\beta}-\hat{\beta}_{\text {median }}^{*}
$$

where $\hat{\beta}$ is the original estimator and $\hat{\beta}_{\text {median }}^{*}$ is the median obtained from the empirical distribution yielded by the bootstrap.

${ }^{25}$ The sizes of the median corrections are available upon request from the authors.
} 


\section{Results}

We examine our results in three steps. First we look at performance changes themselves, and then we report the proportion of the change that can be accounted for by improvements in policymaking. In the last subsection we provide two robustness checks by restricting our analysis to those countries that do not show price-puzzles and also by comparing our method to results available elsewhere for the US using different time periods.

\subsection{Performance Changes}

We estimate models and frontiers for 24 countries over two sample periods, 1983:I-1990:IV and 1991:I-1998:IV. As noted in Section 2, in order to measure inflation and output variability, our baseline assumption is that policymakers are interested in achieving an inflation target of $2 \%$ and in minimizing the variability of output around its potential level, as measured by a Hodrick-Prescott-filtered trend of industrial production. While the $2 \%$ target level for inflation can be viewed as a sensible policy goal during the 1990s, it is less clear that this was the objective pursued by some countries during the 1980s. Still, we adopt the measure of inflation variability using this target level, since we believe a reduction in both average inflation and its variability, for a given variability of output, should be identified with an improved macroeconomic outcome. We note, however, that our results are robust to using the country's average inflation in each period and an H-P filtered series for inflation as targets instead of the $2 \%$ target. ${ }^{26,27}$

Before computing the measures introduced in Section 3, we require a value of the preference parameter $\lambda$. As noted in that section, $\lambda$ can be either estimated within our method or chosen based on plausible values of $\lambda$ obtained elsewhere. Our baseline results are obtained using the latter approach, considering a set of plausible values of $\lambda$ for each of the

\footnotetext{
${ }^{26}$ In a previous version of the paper we also considered a log-linear trend for industrial production as the target level for output, which yields almost identical results as the ones obtained using the H-P filtered series.

${ }^{27}$ The estimates of the measures with alternative targets for inflation and output are available upon request from the authors.
} 
analyzed countries based on the estimates obtained elsewhere by Cecchetti and Ehrmann (2001) and Krause (2003). This procedure means that we do not have to identify a single value of this parameter for each individual country. In the following section, we also show that our results are robust to this choice by considering a range of possible values for $\lambda$ and recomputing our measures. Finally, we also computed our measures based on values of $\lambda$ for each country estimated within our method. The results of this exercise are largely identical to those presented here and are available upon request.

With this in mind, Table 1 reports the value chosen for the inflation variability aversion coefficients and the value of the loss function, $P_{i}$, for the 24 countries in our sample, as well as the percentage change in $P$ between the two periods for each of the countries. We set $\lambda$ equal to 0.8 for all countries, with the exception of Israel, Mexico, Chile and Greece, for which we choose a value of 0.3 . These four countries experienced very high levels of inflation during the 1980s, suggesting that inflation variability must have had a much lower weight in the policymaker's loss function.

Turning to the results, we see in Table 1 that, using our comprehensive measure of performance, only Austria, Germany and Finland exhibited a slight decline in performance while 16 countries experienced sizable improvements. These ranged from $50 \%$ for Canada to over $99 \%$ for Israel. We estimate that performance in Korea and Sweden improved by less than $10 \% .^{28}$

\footnotetext{
${ }^{28}$ Using H-P filtered inflation and log-linear trend for output as targets the results are qualitatively identical to our baseline estimates except that the performance gains for most of the countries are slightly smaller. This is due to the reduction on the variability of inflation resulting from applying the H-P filter. Using average inflation and log-linear trend for output as targets the results are nearly identical to our baseline estimates. The only exceptions are that Austria and Finland now show a modest gain in performance, while Korea shows a moderate performance loss.
} 
Table 1: Value of Loss and Performance Change

\begin{tabular}{|c|c|c|c|c|}
\hline Country & $\begin{array}{c}\text { Value for } \\
\lambda\end{array}$ & $\begin{array}{l}\text { 1983:I-1990:IV: } \\
\text { Value of Loss } \\
\left(10,000 * P_{1}\right)\end{array}$ & $\begin{array}{l}\text { 1991:I-1998:IV: } \\
\text { Value of Loss } \\
\left(10,000 * P_{2}\right)\end{array}$ & $\begin{array}{l}\text { Macroeconomic } \\
\text { Performance } \\
\text { Gain (in \%) }\end{array}$ \\
\hline Australia & 0.8 & 32.780 & 2.175 & $93.37 \%$ \\
\hline Austria & 0.8 & 3.623 & 4.914 & $-35.63 \%$ \\
\hline Belgium & 0.8 & 9.149 & 3.012 & $67.08 \%$ \\
\hline Canada & 0.8 & 11.324 & 5.655 & $50.06 \%$ \\
\hline Chile & 0.3 & 11.382 & 3.325 & $55.50 \%$ \\
\hline Denmark & 0.8 & 553.370 & 246.248 & $70.79 \%$ \\
\hline Finland & 0.8 & 14.642 & 16.304 & $-11.36 \%$ \\
\hline France & 0.8 & 12.857 & 2.320 & $81.95 \%$ \\
\hline Germany & 0.8 & 4.164 & 4.726 & $-13.50 \%$ \\
\hline Greece & 0.3 & 93.360 & 36.196 & $61.23 \%$ \\
\hline Ireland & 0.8 & 19.665 & 7.161 & $63.59 \%$ \\
\hline Israel & 0.3 & 10768.85 & 43.60 & $99.60 \%$ \\
\hline Italy & 0.8 & 40.340 & 6.892 & $82.92 \%$ \\
\hline Japan & 0.8 & 11.264 & 8.804 & $21.85 \%$ \\
\hline Korea & 0.8 & 26.296 & 24.149 & $8.89 \%$ \\
\hline Mexico & 0.3 & 2288.62 & 160.035 & $93.01 \%$ \\
\hline Netherlands & 0.8 & 2.728 & 1.267 & $53.55 \%$ \\
\hline New Zealand & 0.8 & 73.419 & 10.588 & $85.58 \%$ \\
\hline Portugal & 0.8 & 218.901 & 25.981 & $88.13 \%$ \\
\hline Spain & 0.8 & 38.174 & 9.711 & $74.56 \%$ \\
\hline Sweden & 0.8 & 25.118 & 23.106 & $8.01 \%$ \\
\hline Switzerland & 0.8 & 7.228 & 4.733 & $34.52 \%$ \\
\hline U.K. & 0.8 & 17.076 & 3.379 & $80.21 \%$ \\
\hline U.S. & 0.8 & 29.868 & 5.207 & $82.57 \%$ \\
\hline
\end{tabular}

Note: The estimates of the measures are median biased corrected, using the median of the empirical distribution generated by the bootstrap procedure.

How important are these macroeconomic performance improvements? We evaluate this by calculating how much of the performance improvement translates into lower average inflation. That is, we find the inflation that would have had to take place in the second period (as a deviation from $2 \%$ ), holding output variability equal to its first period level, in 
order to explain the performance changes. Put slightly differently, using equation (1), we control for the variability of output and attribute the changes in performance between the two periods only to changes in the average inflation rate (i.e., how close is average inflation to the target level of $2 \%) .{ }^{29}$ Looking at Israel, the $99.6 \%$ performance gain is equivalent to a drop of 179 percentage points in the average annual inflation rate from one period to the next. This is larger than the actual decrease in Israel's annual inflation rate of nearly 120 percentage points between the 1980s and the 1990s. In the case of Australia, the $93.4 \%$ improvement is equivalent to a drop of 4.8 percentage points in the inflation rate, somewhat less than the over 5.9 percentage-point decline experienced there. Finally, for Mexico, the 93.0\% improvement corresponds to a 65 percentage-point drop in inflation, slightly higher than the fall from nearly $70 \%$ to $20 \%$ that actually occurred. Overall, we conclude that large percentage changes in performance signal sizeable macroeconomic improvements.

\subsection{More Efficient Policy or a Calmer World?}

Finally, we have arrived at the primary purpose for deriving all of these measurements: dividing the performance change $\Delta P$ into the portion that is accounted for by improved policy efficiency, $\Delta E$, and the portion due to changes in the variability of supply shocks, $\Delta S$. Given these other measures, we can compute the proportion of performance change that is due to a change in the efficiency of policy, $Q$. We report each of these for all of the countries in our sample. Importantly, in 21 of the 24 countries we study, policy efficiency improved from the 1980s to the 1990s.

Table 2 reports the (bias-corrected) estimates of $\Delta P, \Delta E, Q$, together with the probability that the estimated measures have the incorrect sign. ${ }^{30}$ Out of the 21 countries that experienced a macro performance gain, 14 countries (Australia, Belgium, Chile, Denmark,

${ }^{29}$ The computation of the inflation change that can account for the performance change come from setting $\Delta P$ equal to $P_{1}-\left[\lambda(\Delta \pi-0.02)^{2}+(1-\lambda) \operatorname{Var}\left(y_{1}\right)\right]$.

${ }^{30}$ These probabilities are constructed as follows: If the estimate for the measure is greater than zero, we report the proportion of replications for which the measure is less than zero, divided by the number of bootstrap replications $(1,000)$, and conversely for the case when the estimate is less than zero. 
France, Greece, Israel, Italy, Mexico, New Zealand, Portugal, Spain the UK and the US) experienced both an improvement in macro performance $(\Delta P>0)$ and a reduction in the variability of supply shocks $(\Delta S<0)$. Under these circumstances, $Q$ measures the contribution of a more efficient monetary policy to the improvement of macroeconomic performance. With the exception of Switzerland, all of the estimates suggest that policy has improved, and this improvement is significantly greater than zero at the $10 \%$ level for all of these countries.

Table 2: Estimates of the Measures

\begin{tabular}{|c|c|c|c|c|c|}
\hline \multirow{2}{*}{$\begin{array}{l}\text { Country } \\
\text { Australia }\end{array}$} & \multicolumn{2}{|c|}{$\begin{array}{c}\text { Change in policy } \\
\text { efficiency } \\
(10,000 * \Delta \mathbf{E})\end{array}$} & \multicolumn{2}{|c|}{$\begin{array}{c}\text { Change in macro } \\
\text { performance } \\
(10,000 * \Delta P)\end{array}$} & $\begin{array}{c}\text { Contribution of } \\
\text { policy to change } \\
\text { in performance } \\
(Q=\Delta E / \Delta P)\end{array}$ \\
\hline & 28.98 & $(0.00)$ & 30.60 & $(0.00)$ & $\mathbf{0 . 9 4 7}(0.00)$ \\
\hline Austria & -0.96 & $(0.28)$ & -1.29 & $(0.21)$ & $\mathbf{- 0 . 7 4 4}(0.28)$ \\
\hline Belgium & 5.41 & $(0.10)$ & 6.14 & $(0.06)$ & $\mathbf{0 . 8 8 2}(0.10)$ \\
\hline Canada & 9.14 & $(0.00)$ & 5.67 & $(0.00)$ & $1.612(0.00)$ \\
\hline Chile & 277.55 & $(0.00)$ & 307.12 & $(0.00)$ & $\mathbf{0 . 9 0 4}(0.00)$ \\
\hline Denmark & 7.49 & $(0.00)$ & 8.06 & $(0.00)$ & $\mathbf{0 . 9 3 0}(0.00)$ \\
\hline Finland & 2.46 & $(0.25)$ & -1.66 & $(0.32)$ & $1.481 \quad(0.25)$ \\
\hline France & 9.99 & $(0.00)$ & 10.54 & $(0.00)$ & $0.948 \quad(0.00)$ \\
\hline Germany & -0.59 & $(0.26)$ & -0.56 & $(0.26)$ & $\mathbf{- 1 . 0 4 5}(0.26)$ \\
\hline Greece & 53.31 & $(0.00)$ & 57.16 & $(0.00)$ & $\mathbf{0 . 9 3 3}(0.00)$ \\
\hline Ireland & 12.91 & $(0.00)$ & 12.50 & $(0.29)$ & $1.033 \quad(0.00)$ \\
\hline Israel & 10340 & $(0.00)$ & 10725 & $(0.00)$ & $0.964 \quad(0.00)$ \\
\hline Italy & 33.15 & $(0.00)$ & 33.45 & $(0.00)$ & $0.991(0.00)$ \\
\hline Japan & 2.76 & $(0.24)$ & 2.46 & $(0.27)$ & $1.123 \quad(0.24)$ \\
\hline Korea & 2.88 & $(0.44)$ & 2.15 & $(0.46)$ & $1.344 \quad(0.44)$ \\
\hline Mexico & 2005.6 & $(0.00)$ & 2128.6 & $(0.00)$ & $0.942(0.00)$ \\
\hline Netherlands & 1.97 & $(0.00)$ & 1.46 & $(0.00)$ & $1.352(0.00)$ \\
\hline New Zealand & 56.57 & $(0.04)$ & 62.83 & $(0.02)$ & $0.900 \quad(0.04)$ \\
\hline Portugal & 168.02 & $(0.00)$ & 192.92 & $(0.00)$ & $0.871 \quad(0.00)$ \\
\hline Spain & 25.91 & $(0.00)$ & 28.46 & $(0.00)$ & $0.910 \quad(0.00)$ \\
\hline Sweden & 9.57 & $(0.24)$ & 2.01 & $(0.47)$ & $4.755 \quad(0.24)$ \\
\hline Switzerland & -0.32 & $(0.44)$ & 2.49 & $(0.14)$ & $\mathbf{- 0 . 1 2 8}(0.44)$ \\
\hline U.K. & 11.43 & $(0.02)$ & 13.70 & $(0.01)$ & $\mathbf{0 . 8 3 5}(0.02)$ \\
\hline U.S. & 22.41 & $(0.08)$ & 24.66 & $(0.06)$ & $0.909 \quad(0.08)$ \\
\hline
\end{tabular}

Note: The estimates of the measures are median biased corrected, using the median of the empirical distribution generated by the bootstrap procedure. The probability that the estimate is of the opposite sign is in parenthesis. 
Looking at the final column, the results show that more efficient policy accounted for between $84 \%$ (U.K.) and $99 \%$ (Italy) of the improvement in overall macroeconomic performance. Six other countries (Canada, Ireland, Japan, Korea, Netherlands and Sweden) experienced both a performance gain $(\Delta P>0)$ and an increase in the variability of supply shocks $(\Delta S>0)$. For these countries, the policy efficiency gain has more than offset the higher variability of aggregate shocks and, hence, monetary policy improvements account completely for the observed macro performance gain. More efficient policy is significant at the $10 \%$ level for Canada, Ireland and the Netherlands, but not for Japan, Korea and Sweden. Finally, we also observe that, in all countries that experienced a macro performance improvement (once again, excluding Switzerland), better monetary policy accounts for over 80 percent of the observed performance gain, suggesting that monetary policy has played a far more important role than the reduced variability of shocks in macroeconomic stabilization. This can be clearly seen in Figure 4, which depicts the percentage gain in macro performance and the amount of this gain that is due to more efficient policy. We note that in the majority of the countries we study, the contribution to macro performance by the decrease in the variability of aggregate shocks has been insignificant.

We now turn to the results for the countries that exhibited a macroeconomic performance loss from the 1980s to the 1990s $(\Delta P<0)$, which are only Austria, Finland and Germany. In all cases, our results suggest that the countries were exposed to a higher variability of supply shocks $(\Delta S>0)$. In particular, for the case of Finland more efficient policy was able to partially offset the increased variability of the shocks $(\Delta E>0)$, which implies that the macroeconomic performance loss would have been much larger if not for policy improvement. Nevertheless, neither the performance change, nor the policy efficiency change are significantly different from zero for these three countries, and the performance losses in all cases were quite modest; in no case did it exceed a loss equivalent to an increase of $0.5 \%$ 
in the average inflation rate. ${ }^{31}$

Figure 4: Changes in Performance due to Policy

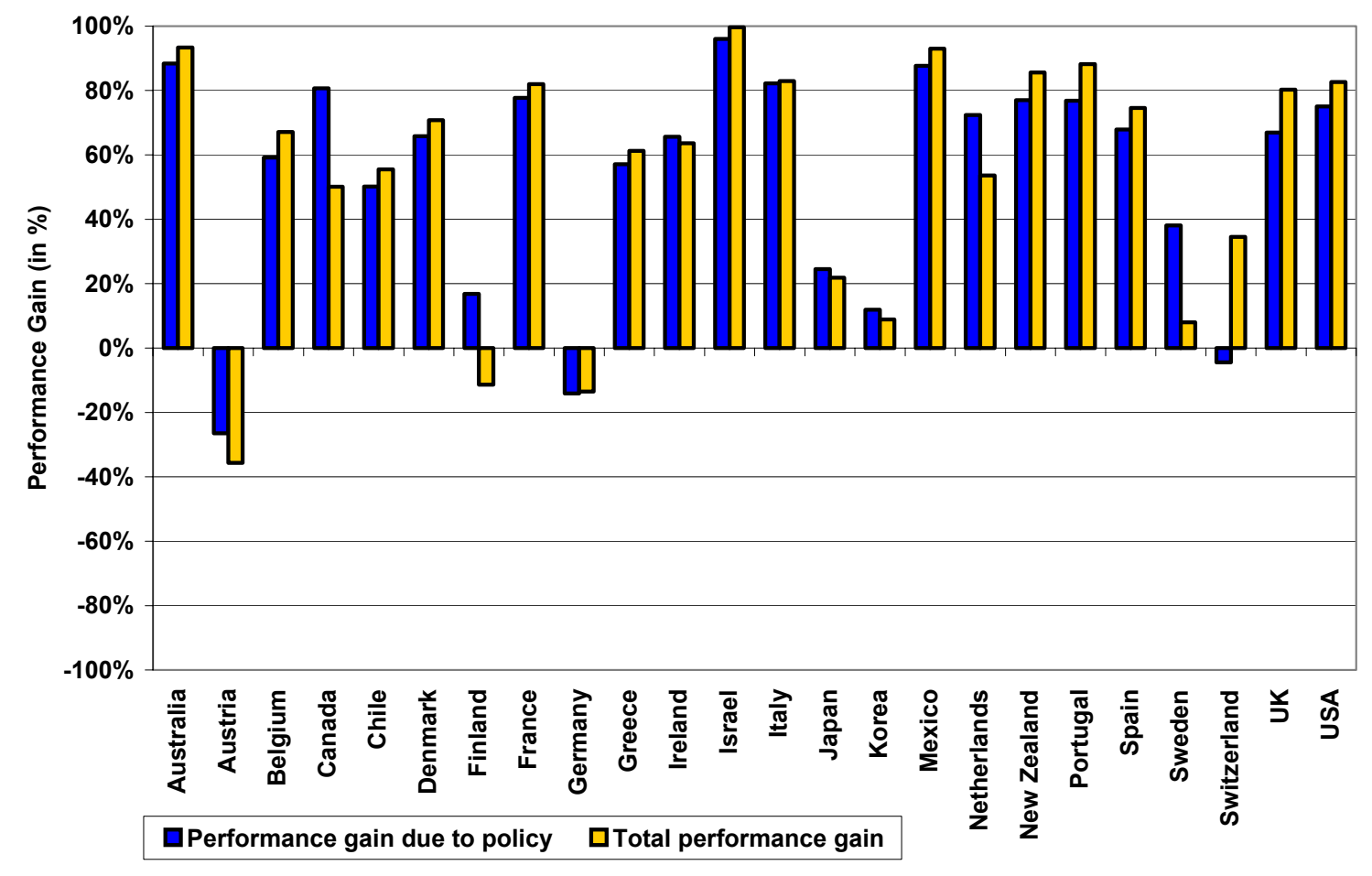

Once again, we can look at examples to see how much improved policy translates into lower average inflation, controlling for the variances around the mean of both inflation and output. For Israel, the efficiency gain amounts to a decrease of 173 percentage points in the average annual inflation rate from one period to the next; for Australia, policy improvement corresponds to a drop of 4.5 percentage points in the inflation rate, while for Mexico it corresponds to a 61.3 percentage-point drop in average inflation.

\footnotetext{
${ }^{31}$ Using average inflation and log-linear trend for output as targets the contribution of policy is nearly identical to our baseline estimates. The only exceptions are Korea, Austria and Finland, since the first one shows a performance loss while the other two show a modest gain. Using H-P filtered inflation and log-linear trend for output as targets the contribution of policy for about half of the countries is smaller, but still more important than the contribution of the reduction of the shocks. Our main conclusions are thus robust to different inflation and output targets.
} 
Table 3: Performance and Efficiency Changes over a range of values for inflation aversion

\begin{tabular}{|c|c|c|}
\hline Country & $\begin{array}{c}\text { Macroeconomic } \\
\text { Performance Gain (in \%) }\end{array}$ & $\begin{array}{c}\text { Contribution of policy to change in } \\
\text { performance }(Q=\Delta E / \Delta P)\end{array}$ \\
\hline Australia & {$[93.3 \%, 93.5 \%]$} & {$[0.945,0.949]$} \\
\hline Austria & {$[-70.5 \%, 17.7 \%]$} & {$[-0.747,1.040]$} \\
\hline Belgium & {$[49.5 \%, 86.4 \%]$} & {$[0.812,0.992]$} \\
\hline Canada & {$[43.9 \%, 60.6 \%]$} & {$[1.424,1.763]$} \\
\hline Chile & {$[52.4 \%, 58.8 \%]$} & {$[0.895,0.912]$} \\
\hline Denmark & {$[54.9 \%, 90.7 \%]$} & {$[0.894,0.977]$} \\
\hline Finland & {$[-119 \%, 69.0 \%]$} & {$[-0.488,36.807]$} \\
\hline France & {$[69.3 \%, 92.7 \%]$} & {$[0.907,1.014]$} \\
\hline Germany & {$[-46.8 \%,-3.9 \%]$} & {$[-2.231,-0.704]$} \\
\hline Greece & {$[61.1 \%, 61.5 \%]$} & {$[0.892,0.949]$} \\
\hline Ireland & {$[41.2 \%, 88.0 \%]$} & {$[0.994,2.673]$} \\
\hline Israel & {$[99.4 \%, 99.7 \%]$} & {$[0.963,0.965]$} \\
\hline Italy & {$[80.7 \%, 84.7 \%]$} & {$[0.983,0.997]$} \\
\hline Japan & {$[2.7 \%, 25.7 \%]$} & {$[1.087,2.765]$} \\
\hline Korea & {$[-6.0 \%, 41.6 \%]$} & {$[-0.342,3.314]$} \\
\hline Mexico & {$[91.9 \%, 93.4 \%]$} & {$[0.941,0.943]$} \\
\hline Netherlands & {$[42.7 \%, 68.0 \%]$} & {$[1.217,1.513]$} \\
\hline New Zealand & {$[73.4 \%, 95.6 \%]$} & {$[0.883,0.911]$} \\
\hline Portugal & {$[84.5 \%, 90.7 \%]$} & {$[0.868,0.873]$} \\
\hline Spain & {$[64.6 \%, 82.1 \%]$} & {$[0.893,0.920]$} \\
\hline Sweden & {$[-53.8 \%, 54.6 \%]$} & {$[0.297,45.013]$} \\
\hline Switzerland & {$[3.8 \%, 47.6 \%]$} & {$[-9.652,0.196]$} \\
\hline U.K. & {$[80.1 \%, 80.3 \%]$} & {$[0.834,0.835]$} \\
\hline U.S. & {$[70.9 \%, 91.1 \%]$} & {$[0.880,0.959]$} \\
\hline
\end{tabular}

Finally, as a robustness check to our choice of inflation aversion parameter, we examine how the estimates of changes in performance and policy efficiency change as we vary $\lambda$. For the countries for which we set $\lambda$ equal to 0.8 , we consider a range of 0.65 to 0.95 . This is consistent with estimates obtained by Cecchetti and Ehrmann (2001) and Krause (2003). 
For the four high inflation countries, where the baseline value of $\lambda$ was set to 0.3 , we consider a range between 0.15 and 0.45 . Results are reported in Table 3 .

Contemplating these ranges for the central bank's preferences, we see that our conclusions are largely unaffected. The only exceptions are Austria, Finland, Korea and Switzerland. In these four cases, changing $\lambda$ can cause a change in the sign for both $\Delta P$ and $Q .{ }^{32}$

\subsection{Robustness Exercises ${ }^{33}$}

In our first exercise we restrict our 24-country sample to those countries that do not show a price-puzzle in the IRFs. The purpose is to analyze whether our results hinge on the arguably failure of the estimated transmission mechanism of a few countries. ${ }^{34}$ Our main results about the contribution of monetary policy to the observed macroeconomic improvement hold for this restricted sample of 16 countries. Out of these countries, 13 of them experienced a macroeconomic performance gain and within them 10 experienced a reduction in the variability of shocks $(\Delta S<0)$. For these countries, improved policy accounted for between 87\% (Portugal) and 95\% (Australia and France). For the 3 remaining countries (Canada, Ireland, and Netherlands), policy efficiency gain still more than offsets the higher variability of aggregate shocks. In summary, our conclusions are unchanged if we restrict our sample to those countries for which the IRFs do not show a price-puzzle. ${ }^{35}$

In the second exercise we reconcile our results with those of Stock and Watson (2003), which, using a different method, attribute the stabilization of output in the US after 1984 to "good luck" (reduction in the variability of shocks) rather than good policies (only about $10 \%$ contribution). The answer to reconciling their apparently opposite results with ours lies in the different subperiods considered by Stock and Watson (pre- and post-1984) and

\footnotetext{
${ }^{32}$ We note again that our results are robust to using estimates of $\lambda$ obtained within our methodology, which are available upon request.

${ }^{33}$ We thank the referees and the editor for suggesting these analyses.

${ }^{34}$ The countries that still present price-puzzles are 8: Israel, Italy, Japan, Korea, Sweden, Switzerland, UK, and the US.

${ }^{35}$ Interestingly, out of the 8 countries that showed ill-behaved IRFs, for 4 of them our measure of the contribution of policy to the change in macro performance (Q) was not significant in Table 2.
} 
their different focus: they focus exclusively on output volatility. Applying our method to the same subperiods considered by Stock and Watson, and setting $\lambda=0$ (i.e. focus exclusively on output volatility) we are able to obtain very similar results to theirs: policy only explains about $18 \%$ of the reduction in output volatility for the US, and the macro performance gain is only $5 \%$. If, as in our analysis, $\lambda$ is set at 0.8 , macro performance gain increases to $11 \%$ and policy explains $45 \%$ of it. Clearly, in our analysis, inflation volatility accounts for much of macro performance, and it is monetary policy that is responsible for that.

\section{Accounting for changes in performance and policy efficiency}

What is responsible for the very pronounced improvements in policy that we have been able to document? Over the past 20 years, much has changed in the 24 countries that we study. Both private and official sector institutions have changed, and dramatically so in some cases. A prime candidate among possible explanations is the institutional framework of central banks. It is natural to ask if the move to more independent and transparent central banks could be responsible for the improvements that we have found.

Addressing this question head on is hampered by data availability. We have no consistent data on changes in independence, transparency and accountability of central banks - those things that theory tell us should matter for the ability of monetary policymakers to do their jobs. Cecchetti and Krause (2002) do look at the relationship between a set of 1998 survey measures of these framework variables and macroeconomic performance and policy efficiency during the 1990s. They find that, with the exception of a combination of transparency and credibility, these end-of-period measures cannot explain the changes over the prior two decades. $^{36}$

It is interesting to go further in assessing the role of central bank independence in ex-

\footnotetext{
${ }^{36}$ Cecchetti and Krause (2002) measure policy credibility by looking at past inflation performance.
} 
plaining the cross-differences in the changes in macroeconomic and policy outcomes. To do this, we construct three measures of the change in independence based on measures from the 1980s. Specifically, we standardize Fry et al.'s (2000) index for independence, which takes a base year 1998, and compare it to the standardized indices from the studies by Alesina (1988), Grilli, Masciandaro and Tabellini (1991) and Cukierman and Lippi (1999) (all of these are only available for a subset of the countries we study); for this last study we use the 1990 data for the independence index. In this way, we obtain three different measures of changes in central bank autonomy and relate them to our measures of performance and policy efficiency.

\section{Table 4: Performance, Efficiency and CB Independence (Correlation coefficients)}

\begin{tabular}{lccc}
\hline & $\begin{array}{c}\text { No. of } \\
\text { countries }\end{array}$ & $\begin{array}{c}\text { Macro } \\
\text { Performance } \\
\text { Change }\end{array}$ & $\begin{array}{c}\text { Policy } \\
\text { Efficiency } \\
\text { Change }\end{array}$ \\
\hline Alesina, 1988 & 15 & 0.329 & 0.430 \\
& & $(0.23)$ & $(0.11)$ \\
Grilli et. al.,1991 & 18 & 0.173 & 0.258 \\
& & $(0.49)$ & $(0.30)$ \\
Cukierman and & 18 & -0.005 & 0.027 \\
Lippi, 1999 & & $(0.99)$ & $(0.92)$ \\
\hline
\end{tabular}

P-values are in parenthesis.

Table 4 presents simple correlations between the three indices of independence changes and our measures of macroeconomic performance and policy efficiency changes. We observe that there is a positive correlation between changes in central bank autonomy and the performance and efficiency loss measures. Unfortunately, none of these correlations is significantly different from zero at even the $10 \%$ level. ${ }^{37}$

\footnotetext{
${ }^{37}$ Another factor that may explain changes in performance and efficiency, as we mentioned in Section 2 , is a shift towards inflation targeting. Looking at the 24 countries, we find evidence pointing to a positive correlation between adopting inflation targeting and better macroeconomic and policy outcomes. This result, however, is mostly due to improvements experienced by three countries (Israel, Mexico and Chile), which
} 
This result, in conjunction with the findings in Cecchetti and Krause (2002), suggests that factors other than the monetary policy framework may account for the cross-country differences in macroeconomic outcomes and policy efficiency. Cecchetti and Krause (2001) explore the possibility that changes in the financial structure may be responsible. They note that a reduction in direct state ownership of bank assets and the introduction of explicit deposit insurance can help explain improvements in measures like $\Delta P$ and $\Delta E$. This is consistent with the lending view of the monetary transmission process, which posits that financial institutions -and their importance as a source of funds for private agents- play a key role in determining the impact policy will have on its goal variables.

Still, in order to determine why countries vary so much in their improvements in performance and policy, we would need to go into more detail by analyzing the events that took place in each country individually during the period under consideration. Such an endeavor is beyond the scope of this study.

\section{Conclusions}

This paper proposes a general method for analyzing changes in macroeconomic performance and identifying the relative contributions of improvements in the efficiency of monetary policy and changes in the variability of aggregate supply shocks. We apply our technique to a cross-section of 24 industrialized and developing countries in order to compare their macroeconomic performance in the 1980s with that in the 1990s. We are able to determine that in 21 of the 24 countries that we study, monetary policy became more efficient in the 1990s.

In 20 of the 21 countries that experienced more stable macroeconomic outcomes, better policy accounted for over $80 \%$ of the measured gain. While policy efficiency improved in Finland, it was unable to completely offset the increased variability of shocks hitting the adopted inflation targeting in the 1990s, as a reaction of the high inflation they had during the 1980s. Controlling for these three cases, the correlation becomes no longer significant. 
economy. Only in Austria and Germany did both policy deteriorate and the variability of supply shocks increase.

Finally, we consider some factors that may help in explaining the cross-country differences in macroeconomic and policy outcomes. Our findings, both in the present paper and in previous research, suggest that elements such as central bank credibility and transparency, together with the nature of the financial system, can account for at least some portion of the observed improvements.

In summary, our results suggest that more efficient policy has been the driving force behind improved macroeconomic performance. At the same time it has also contributed, at least in part, to offsetting an increased variability of supply shocks in some countries. Overall, lower variability of the aggregate supply shocks has usually played a minor role. 


\section{Appendix I: Model Specification}

The basic model consists of two equations. The aggregate demand equation (6) relates (demeaned and detrended) log industrial production to two of its own lags, two lags of the nominal interest rate, one lag of demeaned inflation and one lag of demeaned external price inflation. The aggregate supply equation (7) relates inflation to three of its own lags, one lag of (demeaned and detrended) log industrial production and one lag of demeaned external price inflation. External price inflation is measured by the annualized growth rate in the official exchange rate of the domestic currency vis-a-vis the currency of its main trading partner: Germany for the European countries, Japan for the Asian countries, and the U.S. for the rest. For some countries we also included additional lags, and dummy variables to account for currency crises, sharp recessions, or structural changes. Table A.1 provides a description of all the variables included in the aggregate demand - aggregate supply model for each country. 


\section{Table A.1: Model Specification}

\begin{tabular}{|c|c|c|}
\hline Country & $\begin{array}{l}\text { Explanatory variables in } \\
\text { AD-equation (\# of lags) }\end{array}$ & $\begin{array}{c}\text { Explanatory variables in } \\
\text { AS-equation (\# of lags) }\end{array}$ \\
\hline Australia & $\begin{array}{l}\text { Interest rate (2), Industrial production (2), } \\
\text { Inflation (2), External Inflation (1) }\end{array}$ & $\begin{array}{l}\text { Industrial production (2), Inflation (2), } \\
\text { External Inflation (1) }\end{array}$ \\
\hline Austria & $\begin{array}{l}\text { Interest rate (2), Industrial production (2), } \\
\text { Inflation (2), External Inflation (1) }\end{array}$ & $\begin{array}{l}\text { Industrial production (2), Inflation (2), } \\
\text { External Inflation (1) }\end{array}$ \\
\hline Belgium & $\begin{array}{l}\text { Interest rate (2), Industrial production (2), } \\
\text { Inflation (2), External Inflation (2), Dummy } \\
\text { variable (sharp output decline } 86: I)\end{array}$ & $\begin{array}{l}\text { Industrial production (2), Inflation (2), } \\
\text { External Inflation (1), Dummy variable } \\
\text { (exchange rate crisis 93:I-IV) }\end{array}$ \\
\hline Canada & $\begin{array}{l}\text { Interest rate (2), Industrial production (2), } \\
\text { Inflation (2), External Inflation (1) }\end{array}$ & $\begin{array}{l}\text { Industrial production (2), Inflation (2), } \\
\text { External Inflation (1) }\end{array}$ \\
\hline Chile & $\begin{array}{l}\text { Interest rate (2), Industrial production (2), } \\
\text { Inflation (2), External Inflation (1) }\end{array}$ & $\begin{array}{l}\text { Industrial production (2), Inflation (2), } \\
\text { External Inflation (1), Dummy variable } \\
\text { (increase in money growth 92:I) }\end{array}$ \\
\hline Denmark & $\begin{array}{l}\text { Interest rate (2), Industrial production (2), } \\
\text { Inflation (2), External Inflation (1), Dummy } \\
\text { variable (sharp output decline 86:II-87:I) }\end{array}$ & $\begin{array}{l}\text { Industrial production (2), Inflation (2), } \\
\text { External Inflation (1) }\end{array}$ \\
\hline Finland & $\begin{array}{l}\text { Interest rate (2), Industrial production (2), } \\
\text { Inflation (2), External Inflation (1) }\end{array}$ & $\begin{array}{l}\text { Industrial production (2), Inflation (2), } \\
\text { External Inflation (1), Dummy variable } \\
\text { (exchange rate crisis 92:III-93:IV) }\end{array}$ \\
\hline France & $\begin{array}{l}\text { Interest rate (2), Industrial production (2), } \\
\text { Inflation (2), External Inflation (1) }\end{array}$ & $\begin{array}{l}\text { Industrial production (2), Inflation (2), } \\
\text { External Inflation (1) }\end{array}$ \\
\hline Germany & $\begin{array}{l}\text { Interest rate (2), Industrial production (2), } \\
\text { Inflation (2), External Inflation (1) }\end{array}$ & $\begin{array}{l}\text { Industrial production (2), Inflation (2), } \\
\text { External Inflation (1) }\end{array}$ \\
\hline Greece & $\begin{array}{l}\text { Interest rate (2), Industrial production (2), } \\
\text { Inflation (2), External Inflation (1), Dummy } \\
\text { variable (sharp output decline } 84: \text { I-IV and } \\
93: I-94: I V)\end{array}$ & $\begin{array}{l}\text { Industrial production (2), Inflation (2), } \\
\text { External Inflation (1) }\end{array}$ \\
\hline Ireland & $\begin{array}{l}\text { Interest rate (2), Industrial production (2), } \\
\text { Inflation (2), External Inflation (1) }\end{array}$ & $\begin{array}{l}\text { Industrial production (2), Inflation (2), } \\
\text { External Inflation (1), Dummy variable } \\
\text { (exchange rate crisis 93:I-IV and 95:I-IV) }\end{array}$ \\
\hline Israel & $\begin{array}{l}\text { Interest rate (2), Industrial production (2), } \\
\text { Inflation (2), External Inflation (1) }\end{array}$ & $\begin{array}{l}\text { Industrial production (2), Inflation (2), } \\
\text { External Inflation (1) }\end{array}$ \\
\hline Italy & $\begin{array}{l}\text { Interest rate (2), Industrial production (2), } \\
\text { Inflation (2), External Inflation (1) }\end{array}$ & $\begin{array}{l}\text { Industrial production (2), Inflation (2), } \\
\text { External Inflation (1), Dummy variable } \\
\text { (exchange rate crisis 92:III-93:IV) }\end{array}$ \\
\hline Japan & $\begin{array}{l}\text { Interest rate (2), Industrial production (2), } \\
\text { Inflation (2), External Inflation (1) }\end{array}$ & $\begin{array}{l}\text { Industrial production (2), Inflation (2), } \\
\text { External Inflation (1) }\end{array}$ \\
\hline Korea & $\begin{array}{l}\text { Interest rate (2), Industrial production (2), } \\
\text { Inflation (2), External Inflation (1) }\end{array}$ & $\begin{array}{l}\text { Industrial production (2), Inflation (2), } \\
\text { External Inflation (1) }\end{array}$ \\
\hline Mexico & $\begin{array}{l}\text { Interest rate (2), Industrial production (2), } \\
\text { Inflation (2), External Inflation (1) }\end{array}$ & $\begin{array}{l}\text { Industrial production (2), Inflation (2), } \\
\text { External Inflation (1), Dummy variable } \\
\text { (exchange rate crisis 83:I-IV and 95:I-II) }\end{array}$ \\
\hline Netherlands & $\begin{array}{l}\text { Interest rate (2), Industrial production (2), } \\
\text { Inflation (2), External Inflation (1) }\end{array}$ & $\begin{array}{l}\text { Industrial production (2), Inflation (2), } \\
\text { External Inflation (1) }\end{array}$ \\
\hline New Zealand & $\begin{array}{l}\text { Interest rate (2), Industrial production (2), } \\
\text { Inflation (2), External Inflation (1) }\end{array}$ & $\begin{array}{l}\text { Industrial production (2), Inflation (2), } \\
\text { External Inflation (1), Dummy variable (tax } \\
\text { increases } 85: I, 86: I V \text { and } 89: I I I)\end{array}$ \\
\hline Portugal & $\begin{array}{l}\text { Interest rate (2), Industrial production (2), } \\
\text { Inflation (2), External Inflation (1) }\end{array}$ & $\begin{array}{l}\text { Industrial production (2), Inflation (2), } \\
\text { External Inflation (1), Dummy variable } \\
\text { (exchan. rate crisis 92:IV-93:IV and 95:I-II) }\end{array}$ \\
\hline Spain & $\begin{array}{l}\text { Interest rate (2), Industrial production (2), } \\
\text { Inflation (2), External Inflation (1) }\end{array}$ & $\begin{array}{l}\text { Industrial production (2), Inflation (2), } \\
\text { External Inflation (1), Dummy variable } \\
\text { (exchan. rate crisis 92:IV-93:IV and 95:I-II) }\end{array}$ \\
\hline Sweden & $\begin{array}{l}\text { Interest rate (2), Industrial production (2), } \\
\text { Inflation (2), External Inflation (1) }\end{array}$ & $\begin{array}{l}\text { Industrial production (2), Inflation (2), } \\
\text { External Inflation (1), Dummy variable } \\
\text { (exchange rate crisis 92:III-93:IV) }\end{array}$ \\
\hline Switzerland & $\begin{array}{l}\text { Interest rate (2), Industrial production (2), } \\
\text { Inflation (2), External Inflation (1) }\end{array}$ & $\begin{array}{l}\text { Industrial production (2), Inflation (2), } \\
\text { External Inflation (1) }\end{array}$ \\
\hline UK & $\begin{array}{l}\text { Interest rate (2), Industrial production (2), } \\
\text { Inflation (2), External Inflation (1) }\end{array}$ & $\begin{array}{l}\text { Industrial production (2), Inflation (2), } \\
\text { External Inflation (1), }\end{array}$ \\
\hline USA & $\begin{array}{l}\text { Interest rate (2), Industrial production (2), } \\
\text { Inflation (2), External Inflation (1) }\end{array}$ & $\begin{array}{l}\text { Industrial production (2), Inflation (2), } \\
\text { External Inflation (1) }\end{array}$ \\
\hline
\end{tabular}




\section{Appendix II: Data Sources}

Inflation and Output data for Austria, Belgium, Denmark, Finland, France, Germany, Greece, Ireland, Italy, Netherlands, Portugal, Spain, Sweden and the United Kingdom are

from Datastream; those for Australia, Canada, Japan, Mexico, New Zealand, Switzerland and the United States are taken from the OECD Main Economic Indicators. Data for Chile are from the Central Bank of Chile's WWW-homepage (inflation), and from DRI (industrial production); Israeli data are taken from DRI (industrial production, and inflation). Korea's data are taken from IFS (industrial production) and DRI (inflation). 


\section{References}

[1] Alesina, A. (1988). "Macroeconomics and Politics", in NBER Macroeconomics Annual (edited by Stanley Fisher), Cambridge, MA: MIT Press, pp. 17-52.

[2] Cecchetti, S. G. and M. Ehrmann (2001). "Does Inflation Targeting Increase Output Volatility? An International Comparison of Policymakers' Preferences and Outcomes", in K. Schmidt-Hebbel (ed.), Monetary Policy: Rules and Transmission Mechanisms, Proceedings of the Third Annual Conference of the Central Bank of Chile.

[3] Cecchetti, S. G., A. Flores-Lagunes and S. Krause (2001). "Has Monetary Policy Become More Efficient in Mexico?", Central Bank of Mexico Research Document Series, 2001-01. English version available at http://eller.arizona.edu/ alfonso/cfkmex1102.pdf.

[4] Cecchetti, S. G. and S. Krause (2001). "Financial Structure, Macroeconomic Stability and Monetary Policy", Moneda y Crédito, Madrid, Spain, No. 212 (August 2001), pp. 57-87. (available in English as NBER Working Paper No. 8354).

[5] Cecchetti, S. G. and S. Krause (2002). "Central Bank Structure, Policy Efficiency and Macroeconomic Performance: Exploring Empirical Relationships", Federal Reserve Bank of St. Louis Review, 84 (4) (July/August 2002), pp. 45-60.

[6] Chow, G. C. (1975). Analysis and Control of Dynamic Economic Systems, John Wiley and Sons, New York.

[7] Cukierman, A., and F. Lippi (1999). "Central Bank Independence, Centralization of Wage Bargaining, Inflation and Unemployment: Theory and Some Evidence", European Economic Review, 43, pp. 1395-1434.

[8] Dennis, R. (2001). "The Policy Preferences of the US Federal Reserve", Working Paper No. 01-08, Federal Reserve Bank of San Francisco (revised, June 2003). 
[9] Favero, C. A. and R. Rovelli (2003). "Macroeconomic Stability and the Preferences of the Fed. A Formal Analysis, 1961-98", Journal of Money, Credit and Banking, 35 (4), pp. 545-556.

[10] Freedman, D. and S. Peters (1984). "Bootstrapping a Regression Equation: Some Empirical Results", Journal of the American Statistical Association, 79 (385), pp. 97-106.

[11] Fry, M., D. A. Julius, L. Mahadeva, S. Rogers, and G. Sterne (2000). "Key Issues in the Choice of Monetary Policy Framework," in L. Mahadeva and G. Sterne (eds.), Monetary Policy Framework in a Global Context, Routledge, London, United Kingdom.

[12] Grilli, V., Masciandaro, D. and G. Tabellini (1991). "Political and Monetary Institutions and Public Financial Policies in the Industrial Countries", Economic Policy, 13, pp. 341392.

[13] Kahn, J., M. M. McConnell and G. Pérez-Quirós (2002). "On the Causes of the Increased Stability of the U.S. Economy" Economic Policy Review, 8 (May 2002), pp. 183-202.

[14] Krause, S. (2003). "Measuring Monetary Policy Efficiency in European Union Countries: The Pre-EMU years", Working Paper 03-11, Department of Economics, Emory University.

[15] Li, H. and G. S. Maddala (1996). "Bootstrapping Time Series Models", Econometrics Reviews, 15 (2), pp. 115-158.

[16] Phillips, P. C. B. and P. Perron (1988). "Testing for a Unit Root in Time Series Regression", Biometrika, 75, pp. 335-346.

[17] Rudebusch, G. D. and L. E. O. Svensson (1999). "Policy Rules for Inflation Targeting" in J. B. Taylor (ed.), Monetary Policy Rules, University of Chicago Press, Chicago, pp. 203-246. 
[18] Sims, C. (1992). "Interpreting the Macroeconomic Time Series Facts: The Effects of Monetary Policy", European Economic Review, 36, pp. 975-1000.

[19] Stock, J. H. and M. W. Watson (2003). "Has the Business Cycle Changed? Evidence and Explanations" manuscript prepared for the Federal Reserve Bank of Kansas City Symposium: Monetary Policy and Uncertainty.

[20] Svensson, L. E. O. (1997). "Inflation Forecast Targeting: Implementing and Monitoring Inflation Targets", European Economic Review, 41, pp. 1111-1146.

[21] Taylor, J. B. (1979). "Estimation and Control of a Macroeconomic Model with Rational Expectations", Econometrica, 47, pp. 1267-1286. 